\title{
Association of GNB3 C825T polymorphism with plasma electrolyte balance and susceptibility to hypertension
}

\author{
Azim Nejatizadeh ${ }^{1}$, Rahul Kumar ${ }^{2}$, Tsering Stobdan ${ }^{2}$ and Mohammad Qadar Pasha ${ }^{2}$ \\ ${ }^{1}$ Research Center for Molecular Medicine, Hormozgan University of Medical Sciences, Bandar Abbas, Iran. \\ ${ }^{2}$ Institute of Genomics and Integrative Biology, Delhi, India.
}

\begin{abstract}
The role of G-protein activation in cardiovascular disorders is well-known. G-protein $\beta 3$ subunit (GNB3) C825T polymorphism is associated with increased intracellular signal transduction. We investigated the role of the variant in plasma sodium and potassium concentrations and association with hypertension. 345 healthy controls and 455 patients with essential hypertension were enrolled. Plasma renin activity and aldosterone concentration were measured. The variant, typed by SNaPshot, was analyzed on an ABI Prism 3100 Genetic Analyzer and GeneScan. The TT genotype and T allele were over-represented in the patients $(p<0.001, p<0.0001)$. Multiple-logistic regression disclosed that the risk of hypertension was significantly greater for TT $(p<0.0001, \mathrm{OR}=6.1, \mathrm{Cl}=2.9-12.7)$. One-way ANOVA revealed that hypertensive T-allele carriers (CT+TT), compared to non-carriers (CC), had a greater body mass index (BMI), mean arterial pressure (MAP) and PAC $(p=0.01, p=0.01, p<0.0001$, respectively); while the patients with 825TT risk genotype showed higher plasma sodium and lower potassium $(p<0.0001$, each). The results strongly emphasize, not only the role of C825T polymorphism by the induction of increased G-protein activity and enhancement of $\mathrm{Na} / \mathrm{h}$ exchangers, but also the association with higher plasma sodium and lower potassium levels, high BMI and susceptibility to hypertension.
\end{abstract}

Key words: GNB3 C825T polymorphism, hypertension, G protein, plasma electrolytes.

Received: December 18, 2010; Accepted: July 14, 2011.

It is widely accepted that nearly all transmembrane receptors, as well as various vasoactive/growth-stimulating factors in cardiovascular homeostasis and peripheral vascular resistance, depend on G-proteins to regulate intracellular signaling cascades (Siffert et al., 1995). An increased activity of G-protein enhances the $\mathrm{Na} / \mathrm{h}$ exchanger (NHE1) in almost $50 \%$ of the patients with Essential Hypertension $(\mathrm{EH})$, gives evidence of the role of these proteins in the pathogenesis of essential hypertension (EH) (Siffert and Düsing, 1995; Schunkert et al., 1998). The GNB3 C825T polymorphism results in alternative splicing of exon 9 that eliminates 41 amino acids in the protein, thereby associating with the expression of a novel splice-variant (G $\beta 3$-s) that correlates with enhanced G-protein activation. This has been investigated, in order to establish an association with blood pressure, hypertension, body-mass index, left-ventricular hypertrophy and related phenotypes (Siffert, 1996; Schunkert et al., 1998; Siffert et al., 1999b; Poch et al., 2000). On recognizing the significance of GNB3 C825T polymorphism in susceptibility to hypertension, we undertook an association study with a case-control design. Since

Send correspondence to Azim Nejatizadeh. Research Center for Molecular Medicine, Hormozgan University of Medical Sciences, Bandar Abbas, Iran. E-mail: azimnejate@yahoo.com. alterations in electrolyte balance can be through increased G-protein activity, the next step was to evaluate association of the variant with plasma-sodium and potassium concentrations.

The study was approved by the ethical committee. Each of the subjects involved signed an informed consent form. Study subjects consisted of 345 consecutive unrelated sex-matched healthy controls and $455 \mathrm{EH}$ patients, so diagnosed through Hypertension outpatient clinics of collaborating hospitals. Details of selection criteria have already been presented in an earlier work (Nejatizadeh et al., 2008). No exercise, alcohol, caffeine or smoking was allowed, for a period of $30 \mathrm{~min}$ prior to blood-pressure measurement. Blood pressure (BP) was measured by conventional mercury sphygmomanometer. Measurements by two different observers were taken at the left arm in the seated position after $15 \mathrm{~min}$ of rest. This procedure was repeated three times, systolic BP (SBP) and diastolic BP (DBP) being defined as the mean of the three independent measurements. According to the JNC VII panel, hypertension was defined as an average SBP of $\geq 140 \mathrm{~mm} \mathrm{Hg}$, an average DBP of $\geq 90 \mathrm{~mm} \mathrm{Hg}$ (or both), or as a diagnosis of hypertension in subjects receiving antihypertensive medication. Demographic data were collected by means of a detailed 
standard questionnaire. There was also a detailed interview, physical examination and laboratory analysis. Blood samples were collected after $12 \mathrm{~h}$ overnight fasting. Cells were used for DNA extraction and plasma for biochemical analysis. The latter was stored at $-80^{\circ} \mathrm{C}$ if not analyzed immediately. GNB3 C $825 \mathrm{~T}$ polymorphism was genotyped, and the effect of the genetic variant on clinical and biochemical parameters monitored in both study groups. Plasma renin activity (PRA) and plasma aldosterone concentration (PAC) were measured by radioimmunoassay $(\mathrm{M} / \mathrm{s}$ Immunotech, France). The counts were measured in duplicate on a gamma counter (Ria Calc WIZARD 1470, USA). The variant was typed by an SNaPshot ddNTP Primer Extension Kit (Applied Biosystems, Foster City, Calif), electrophoresed on an ABI Prism 3100 Genetic Analyzer (Applied Biosystems), and subsequently analyzed on an ABI Prism GeneScan and Genotyper (Applied Biosystems). Sodium, calcium, potassium, total cholesterol, triglyceride, uric acid, creatinine, and glucose, were all measured on a highthroughput autoanalyzer (Elecsys 2010, Roche, Germany). Estimates were obtained in duplicate. Intra- and inter-assay coefficients of variation were less than $5 \%$. All statistical analyses were carried out with SPSS 12.0 (SPSS Inc., Chicago, Illinois, USA), and EPIINFO v. 6 softwares. HardyWeinberg equilibrium (HWE) with $1 d f$ a goodness of fit test was calculated using the DeFinetti program. Allele and genotype frequencies were estimated by gene counting. Categorical and continuous variables were compared using $\chi^{2}$-test and unpaired Student's t-test. Logistic regression analysis was undertaken with different models. Odds ratio (OR) was calculated through logistic regression. Where appropriate, correction for multiple testing was made by Bonferroni correction test. Power calculations were performed with the PS: Power and Sample Size Calculation program by Dupont and Plummer. A two-tailed $p$ value of $<0.05$ was considered statistically significant.
The overall percentage of successful genotyping was at least 99,4\%. Genotype distribution was at Hardy-Weinberg equilibrium $(\mathrm{p}=\mathrm{NS})$. As the TT genotype was overrepresented in the patients $\left(\operatorname{LRT} \chi^{2}=16.2, d f=2, \mathrm{p}<0.001\right.$, Table 1), consequently, the $\mathrm{T}$ allele was also $\left(\right.$ LRT $\left.^{2}=25.9, d f=1, \mathrm{p}<0.0001\right)$. Multiple-logistic regression analysis revealed that the risk of hypertension was significantly higher for the TT genotype $(\mathrm{p}<0.0001$, $\mathrm{OR}=6.1$, Wald's $95 \% \mathrm{CI}=2.9-12.7$ ) (Table 1). Significance was maintained even after adjustment by age, sex and BMI $(p<0.001)$. Significant probability values and relative risks for C825T polymorphism were obtained by implementing recessive $(\mathrm{p}<0.0001, \mathrm{OR}=5.0$, Wald's $95 \%$ $\mathrm{CI}=2.4-10.2)$ and additive models $(\mathrm{p}<0.0001, \mathrm{OR}=5.0$, Wald's 95\% CI $=2.9-8.4$ ). Homozygous $825 \mathrm{~T}$ allele carriers showed considerable relative risk, with a six-fold higher chance of developing hypertension compared to homozygous $825 \mathrm{C}$ allele carriers. One-way ANOVA revealed that in hypertensive T-allele carriers (CT+TT), BMI, mean arterial pressure (MAP) and PAC were higher $(p=0.01$, $\mathrm{p}=0.01, \mathrm{p}<0.0001$, respectively), when compared to noncarriers (CC) (Table 1), whereas patients with the 825TT risk genotype had higher plasma sodium, serum creatinine and urea, and lower potassium levels $(\mathrm{p}<0.0001$, each) (Table 2). In an association of the 825T allele with MAP and PAC, increased plasma sodium and decreased potassium concentrations were observed ( $p<0.0001$, each).

Worthy of note, our study revealed for the first time an association among Asians of the $825 \mathrm{~T}$ allele with MAP and PAC, increased plasma sodium and decreased potassium concentrations, which could reflect an enhanced activity of NHE-1 in hypertension. Furthermore, the highly significant PAC and low PRA in patients suggested of a low renin hypertension (Nejatizadeh et al., 2008). Notwithstanding, studies of ethnic groups are not devoid of conflict (Beige et al., 1999; Brand et al., 1999; Larson et al., 2000;

Table 1 - Distribution of alleles and genotype frequency of the GNB3 C825T polymorphism between patients and controls.

\begin{tabular}{|c|c|c|c|c|c|c|}
\hline Genotypes & Patients $(n=449)$ & Controls $(n=345)$ & $\mathrm{OR}^{\dagger}$ & $95 \% \mathrm{CI}^{*}$ & $\chi^{2}$ & $\mathrm{p}^{*}$ \\
\hline $\mathrm{CC}$ & $185(41 \%)$ & $192(56 \%)$ & - & & & \\
\hline $\mathrm{CT}$ & $211(47 \%)$ & $144(42 \%)$ & 1.5 & $(1.1-2.0)$ & 7.91 & 0.005 \\
\hline TT & $53(12 \%)$ & $09(02 \%)$ & 6.1 & $(2.9-12.7)$ & 28.4 & 0.0000 \\
\hline $\mathrm{C}$ & $581(65 \%)$ & $528(77 \%)$ & & & & \\
\hline $\mathrm{T}$ & $317(35 \%)$ & $162(23 \%)$ & 1.8 & $(1.4-2.2)$ & 25.9 & 0.0000 \\
\hline HWE & $\chi^{2}=0.05, p=0.97$ & $\chi^{2}=2.95, p=0.22$ & & & & \\
\hline Recessive model & & & 5.0 & $(2.4-10.2)$ & 22.9 & 0.0000 \\
\hline Dominant model & & & 5.0 & $(0.4-0.7)$ & 16.3 & 0.0000 \\
\hline Additive model & & & 5.0 & $(2.9-8.4)$ & 43.0 & 0.0000 \\
\hline
\end{tabular}

†OR (CI \%95), indicates crude odds ratio and $95 \%$ confidence interval. ${ }^{\star} \mathrm{OR}$ denotes adjusted odds ratio by age, sex and BM I. *p values are calculated by logistic regression. Number of the individuals (\%) Dominant model compares a combination of heterozygous and homozygous genotypes of the least frequent allele to homozygotes of the most frequent. Recessive model compares a combination of heterozygous and homozygous genotypes of the most frequent allele to the variant allele homozygous genotype. Additive model compares a combination of the two genotypes with weight 2 and 1 respectively to the homozygote of the most frequent allele. 
Table 2 - Anthropometric and demographic data in hypertensive patients according to 825C/T polymorphism of the GNB3 gene.

\begin{tabular}{|c|c|c|c|c|c|c|}
\hline Parameter & $\mathrm{CC}(\mathrm{n}=179)$ & $\mathrm{CT}(\mathrm{n}=220)$ & $\mathrm{TT}(\mathrm{n}=50)$ & $\mathrm{p}^{*}$ & $\mathrm{CT}+\mathrm{TT}(\mathrm{n}=270)$ & $\mathrm{p}^{\dagger}$ \\
\hline Age, yr & $50.1 \pm 11.6$ & $52.6 \pm 12$ & $51.8 \pm 9.1$ & 0.1 & $52.2 \pm 10.5$ & 0.05 \\
\hline Gender, \% & 58.1 & 58.6 & 62 & 0.83 & 60.3 & 0.77 \\
\hline BMI, $\mathrm{kg} / \mathrm{m}^{2}$ & $23.8 \pm 3.7$ & $24.5 \pm 4.4$ & $24.8 \pm 2.8$ & 0.13 & $24.65 \pm 3.6$ & 0.01 \\
\hline $\mathrm{SBP}, \mathrm{mmHg}$ & $168 \pm 18.2$ & $169 \pm 18$ & $171.3 \pm 17$ & 0.51 & $170 \pm 34.5$ & 0.45 \\
\hline DBP, $\mathrm{mmHg}$ & $99.4 \pm 8.4$ & $100 \pm 10$ & $102 \pm 8$ & 0.21 & $101 \pm 9$ & 0.04 \\
\hline MAP, $\mathrm{mmHg}$ & $121 \pm 15.3$ & $123 \pm 10$ & $125 \pm 9$ & 0.08 & $124 \pm 9.5$ & 0.01 \\
\hline $\mathrm{PP}, \mathrm{mmHg}$ & $67.6 \pm 16$ & $69.2 \pm 18$ & $69 \pm 16$ & 0.63 & $69.1 \pm 17$ & 0.35 \\
\hline PAC, Pmole/L & $155 \pm 41$ & $220 \pm 62$ & $255 \pm 6$ & $<0.0001$ & $237.5 \pm 65$ & $<0.0001$ \\
\hline Serum $\mathrm{Na}^{+}, \mathrm{mmol} / \mathrm{L}$ & $135 \pm 7.8$ & $137 \pm 6.6$ & $142 \pm 7.2$ & $<0.0001$ & $139.5 \pm 6.9$ & $<0.0001$ \\
\hline Serum $\mathrm{K}^{+}, \mathrm{mmol} / \mathrm{L}$ & $4.5 \pm 0.8$ & $4.6 \pm 0.85$ & $5.0 \pm 0.54$ & 0.0005 & $4.8 \pm 0.69$ & 0.00008 \\
\hline Serum creatinine, $\mathrm{mg} / \mathrm{dL}$ & $1.1 \pm 0.48$ & $1.32 \pm 0.6$ & $1.41 \pm 0.5$ & 0.000002 & $1.36 \pm 0.55$ & $<0.0001$ \\
\hline Serum urea, $\mathrm{mg} / \mathrm{dL}$ & $32 \pm 8$ & $35 \pm 8.5$ & $36.4 \pm 7.2$ & 0.0001 & $35.7 \pm 7.85$ & 0.000005 \\
\hline Total cholesterol, mg/dL & $110 \pm 40$ & $107 \pm 39$ & $108 \pm 32$ & 0.78 & $107.5 \pm 35$ & 0.85 \\
\hline Triglyceride, mg/dL & $100 \pm 30$ & $105 \pm 35$ & $90 \pm 25$ & & $0.1996 \pm 29$ & 0.46 \\
\hline Uric acid, mg/dL & $5.2 \pm 1.6$ & $5.3 \pm 1.5$ & $5.5 \pm 1.7$ & & $0.47 \pm 1.6$ & 0.19 \\
\hline
\end{tabular}

Values are mean \pm STD. BMI indicates body-mass index; SBP, systolic blood pressure; DBP, diastolic blood pressure; MAP, mean arterial pressure; PP, pulse pressure; $\mathrm{Na}^{+}$, sodium; $\mathrm{K}^{+}$, potassium; $\mathrm{Ca}^{+}$, calcium. CC, CT, TT, and CT $+\mathrm{TT}$ refer to genotype groups described in this study. ${ }^{*}$ Statistical analysis was performed by analysis of variance among the 3 genotypes. "Statistical analysis was performed by Student's t-test for CT +TT $v s$. CC genotypes.

Staessen et al., 2003). Our findings are in accordance with those of Siffert (2000). It is well-established that obesity, salt retention and low plasma renin activity are associated with NHE-1 hyperactivity (Delva et al., 1993; Diez et al., 1995). As enhanced NHE-1 activity is subject to G-protein hyperactivation in the presence of the $825 \mathrm{~T}$ allele, a consequential increase of these phenotypes in $825 \mathrm{~T}$ allele carriers is to be expected. Furthermore, the association of this allele with obesity could not be overlooked, since BMI in $\mathrm{T}$-allele carriers (CT+TT) higher than in non-carriers (CC), thus in agreement with an earlier report (Siffert et al., 1999b). Although, G proteins are known to play a key role in adipogenesis and $825 \mathrm{~T}$ alleles predict enhanced $\mathrm{G}$ protein activation, the association between $825 \mathrm{~T}$ allele and obesity cannot attenuate the influence of non-genetic factors, such as life-style, for a susceptibility gene to present its effect on obesity. Predictably, the $825 \mathrm{~T}$ allele increases the risk of obesity, which, over the years, leads to hypertension.

Moreover, given the causative nature of the C825T variant, it is likely that the vasoconstrictors, norepinephrine and angiotensin II, also transmit their effect to pertussis toxin-sensitive $\mathrm{G}$ proteins, which, in turn, enhance vascular resistance in individuals carrying mutated GNB3 proteins. It is known that angiotensin II, as a main stimulator of aldosterone, can act via Gi proteins, thereby enhancing phospholipase $\mathrm{C}$ activity, cytosolic calcium liberation, and CYP11B2 gene expression (Lu et al., 1996). Therefore, in brief, in hypertensive TT carriers, lower angiotensin II levels are regulated by increased postreceptor signaling and subsequent high aldosterone and suppressed renin levels, thus emphasizing $825 \mathrm{~T}$ allele efficacy for enhancing intracellular signal transduction in humans. In conclusion, our results strongly suggest the contribution of GNB3 C825T polymorphism to the risk of essential hypertension and high BMI, and also highlight the role of increased $\mathrm{Na}^{+}-\mathrm{H}^{+}$ exchanger activity. Of course, it is likely that this association could have arisen from a direct physiological effect of the genetic variation or linkage disequilibrium, with an additional functional alteration at the GNB3 locus. Nonetheless, validation of the functionality of the $825 \mathrm{~T}$ allele, nonetheless, is desirable, as a means of establishing its causative role. Moreover, the role of other variants in or near GNB3 cannot be overlooked. The identification and functional significance of novel polymorphisms, such as A $(-350) \mathrm{G}$ in the promoter region and $\mathrm{A} C 1429 \mathrm{~T}$ in the 3 '-untranslated region of the GNB3, having occurred with variable frequency in several ethnic groups, including black Africans, Chinese, and Germans, have also been investigated (Rosskopf et al., 2000). Another assumption is that GNB3 825T, possibly in concert with these and other variants, influences variations in blood pressure and bodyweight. Additional work will be needed to elucidate the associations between these polymorphisms and G-protein functions.

Interaction analysis of the GNB3 gene with other genes involved in $\mathrm{G}$ protein-mediated pathways may be helpful in developing an understanding of the association between $\mathrm{G}$ protein-mediated pathways and cardiovascular diseases. Despite universal recognition that blood pressure 
is influenced by interactions between the effects of several genetic and environmental factors, the possibility of detecting statistically significant interactions between genetic effects measured by gene polymorphisms, and effects of other genetic and environmental factors, have received wide attention. Such interactions may give rise to the different relationships between genotypic and phenotypic variations in diverse environments. Genotyping of these polymorphisms, along with a positive family history of cardiovascular disease, could help in identifying individuals with high susceptibility to EH.

\section{Acknowledgments}

Hormozgan University of Medical Sciences in Iran and the Indian Council of Scientific and Industrial Research afforded financial support to this work. The staff at the Departments of the two hospitals is acknowledged for their cooperation.

\section{References}

Beige J, Hohenbleicher H, Distler A and Sharma AM (1999) G-Protein beta-3 Subunit C825T variant and ambulatory blood pressure in essential hypertension. Hypertension 33:1049-1051.

Brand E, Herrmann SM, Nicaud V, Ruidavets JB, Evans A, Arveiler D, Luc G, Plouin PF, Tiret L and Cambien F (1999) The $825 \mathrm{C} / \mathrm{T}$ polymorphism of the G-protein subunit beta-3 is not related to hypertension. Hypertension 33:1175-1178.

Delva P, Pastori C, Provoli E, Degan M, Arosio E, Montesi G, Steele A and Lechi A (1993) Erythrocyte Na+-H+ exchange activity in essential hypertensive and obese patients: Role of excess body weight. J Hypertens 11:823-830.

Diez J, Alonso A, Garciandia A, López R, Gómez-Alamillo C, Arrázola A and Fortuño A (1995) Association of increased erythrocyte $\mathrm{Na}+/ \mathrm{H}+$ exchanger with renal $\mathrm{Na}+$ retention in patients with essential hypertension. Am J Hypertens 8:124-132.

Larson N, Hutchinson R and Boerwinkle E (2000) Lack of association of 3 functional gene variants with hypertension in African Americans. Hypertension 35:1297-1300.

Lu HK, Fern RJ, Luthin D, Linden J, Liu LP, Cohen CJ and Barrett PQ (1996) Angiotensin II stimulates T-type Ca2+ channel currents via activation of $\mathrm{G}$ protein, Gi. Am J Physiol 271:1340-1349.

Nejatizadeh A, Kumar R, Stobdan T, Goyal AK, Gupta M, Javed S and Pasha MQ (2008) Significance of angiotensinogen gene haplotypes and genotypes combinations in hypertension. J Hypertens 260:1094-1101.
Poch E, Gonzalez D, Gomez-Angelats E, Enjuto M, Paré JC, Rivera F and de La Sierra A (2000) G-Protein $\beta$ (3) subunit gene variant and left ventricular hypertrophy in essential hypertension. Hypertension 35:214-218.

Rosskopf D, Busch S, Manthey I and Siffert W (2000) G protein b3 gene. Structure, promoter, and aditional polymorphisms. Hypertension 2000:36:33-41.

Schunkert H, Hense HW, Döring A, Riegger AJ and Siffert W (1998) Association between a polymorphism in the G protein $\beta-3$ subunit gene and lower renin and elevated diastolic blood pressure levels. Hypertension 32:510-513.

Siffert WG (1996) Proteins, hypertension, and coronary heart disease: Novel findings and hypotheses. Kidney Blood Press Res 1996 19:71-80.

Siffert WG (2000) Protein beta 3 subunit 825T allele, hypertension, obesity, and diabetic nephropathy. Nephrol Dialysis Transplant 15:1298-1306.

Siffert W and Düsing R (1995) Sodium-proton exchange and primary hypertension: An update. Hypertension 26:649-655.

Siffert W, Rosskopf D, Moritz A, Wieland T, Kaldenberg-Stasch S, Kettler N, Hartung K, Beckmann S and Jakobs KH (1995) Enhanced $G$ protein activation in immortalized lymphoblasts from patients with essential hypertension. J Clin Invest 96:759-766.

Siffert W, Forster P, Jöckel KH, Mvere DA, Brinkmann B, Naber C, Crookes R, Du P Heyns A, Epplen JT, Fridey J, et al. (1999a) Worldwide ethnic distribution of the G protein beta3 subunit $825 \mathrm{~T}$ allele and its association with obesity in Caucasian, Chinese, and Black African individuals. J Am Soc Nephrol 10:1921-1930.

Siffert W, Naber C, Walla M and Ritz E (1999b) G protein $\beta-3$ subunit $825 \mathrm{~T}$ allele and its potential association with obesity in hypertensive individuals. J Hypertens 17:1095-1098.

Staessen A, Wang J, Bianchi G and Birkenhager WH (2003) Essential hypertension. Lancet 361:1629-1641.

\section{Internet Resources}

DeFinetti program, http://ihg.gsf.de/cgi-bin/hw/hwa1.pl.

PS: Power and Sample Size Calculation program, by William D. Dupont and Walton D. Plummer, Jr., http://biostat.mc. vanderbilt.edu/twiki/bin/view/Main/PowerSampleSize.

Note that the information previously found at http://www.mc.vanderbilt.edu/prevmed/ps/index.htm has been moved to http://biostat.mc.vanderbilt.edu/twiki/bin/ view/Main/PowerSampleSize.

Associate Editor: Angela M. Vianna-Morgante

License information: This is an open-access article distributed under the terms of the Creative Commons Attribution License, which permits unrestricted use, distribution, and reproduction in any medium, provided the original work is properly cited. 